CAPSULE COMMENTARIES

\title{
Capsule Commentary on Ganguli et al., Ebola Risk and Preparedness: A National Survey of Internists
}

\author{
Jeffrey L. Jackson, MD, MPH \\ Zablocki VAMC, Milwaukee, WI, USA. \\ J Gen Intern Med 31(3):321 \\ DOI: $10.1007 / \mathrm{s} 11606-015-3570-5$ \\ (c) Society of General Internal Medicine 2016
}

$\mathrm{H}$ ealth risk communication is an ongoing problem in health systems worldwide. Heightened awareness of increasingly deadly diseases can have a downside, as patients and their providers may be needlessly concerned that they could have a potentially deadly disease. While the CDC maintains up-to-date information on criteria for diagnosing infectious diseases, these guidelines are not always appropriately followed. For example, last month I was ward-attending and post-call, found that a 25-year-old Middle-Eastern man had been admitted to an isolation room over concern that he might have Middle East Respiratory Syndrome. He had just returned from a month backpacking across Europe. He had not travelled to the Middle East and had no known contact with anyone who had. He and his family were terrified, and it took considerable persuasion to convince them it was safe for him to go. Clinicians pride themselves on having a broad differential, but relying on heuristics, particularly for unusual diagnoses, can be problematic. Ganguli et al. surveyed internists about another emerging infection, Ebola, and found that while most respondents felt confident that they could recognize and take appropriate steps to manage Ebola, those at low risk of encountering Ebola were likely to be overly aggressive in managing low-risk patients. ${ }^{1}$

It is heartening that most of these researchers found that clinicians reported reviewing CDC guidelines, as these provide up-to-date information on diagnosing and managing emerging diseases. Ganguli suggests that additional mechanisms for educating doctors might include outreach with pro-

fessional groups, electronic decision support, or governmentmandated training. In an increasingly electronic world, clinicians have access to a considerable amount information. ${ }^{2},{ }^{3}$ Some state health agencies are turning more and more to social media to convey health messages and information, for both consumers and providers. ${ }^{4}$ Health consumers ${ }^{5}$ and providers ${ }^{1}$ use multiple sources of information during heightened periods of concern. Public health agencies must collaborate with the media to ensure that accurate messages get out to the public. ${ }^{3}$ State health agencies can also provide reassurance and information to providers who face clinical scenarios in which rare diseases are on the differential.

Corresponding Author: Jeffrey L. Jackson, MD, MPH; Zablocki VAMC, Milwaukee, WI, USA (e-mail: jjackson@mcw.edu).

\section{Compliance with Ethical Standards:}

Conflict of Interest: The author has no conflicts of interest with this article.

\section{REFERENCES}

1. Ganguli I, Chang Y, Weissman A, Armstrong K, Metlay J. Ebola Risk and Preparedness: A National Survey of Internists. J Gen Intern Med. (DOI:10. 1007/s11606-015-3493-1).

2. Wu HM, Fairley JK, Steinberg J, Kozarsky P. The potential Ebola-infected patient in the ambulatory care setting: preparing for the worst without compromising care. Ann Intern Med. 2015; 162:66-7.

3. Kostkova P, Fowler D, Wiseman S, Weinberg JR. Major infection events over 5 years: how is media coverage influencing online information needs of health care professionals and the public? J Med Internet Res. 2013;15(7):e107.

4. Jha A, Lin L, Savoia E. The use of social media by state health departments in the US: analyzing health communication through Facebook. J Communty Health. 2015. Aug 29

5. Jardine CG, Boerner FU, Boyd AD, Driedger SM. The more the better? A comparison of the information sources used by the public during two infectious disease outbreaks. Plos One. 2015;10(10), e0140028.

This comment refers to the article available at: http://dx.doi.org/10.1007/ s11606-015-3493-1.

Published online January 11, 2016 